Research Paper

\title{
Capping Agent-Dependent Toxicity and Antimicrobial Activity of Silver Nanoparticles: An In Vitro Study. Concerns about Potential Application in Dental Practice
}

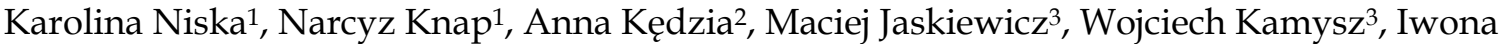 \\ Inkielewicz-Stepniak ${ }^{1 凶}$ \\ 1. Department of Medical Chemistry, Medical University Gdansk, Poland \\ 2. Department of Oral Microbiology, Medical University Gdansk, Poland \\ 3. Department of Inorganic Chemistry, Medical University Gdansk, Poland \\ $\triangle$ Corresponding author: Address: Department of Medical Chemistry, Medical University of Gdansk, Debinki St., 80-211 Gdansk, phone: 0048 58349 1450 , \\ Poland. e-mail address: iinkiel@gumed.edu.pl
}

(1) Ivyspring International Publisher. Reproduction is permitted for personal, noncommercial use, provided that the article is in whole, unmodified, and properly cited. See http://ivyspring.com/terms for terms and conditions.

Received: 2016.04.29; Accepted: 2016.07.27; Published: 2016.09.27

\begin{abstract}
Objectives: In dentistry, silver nanoparticles (AgNPs) have drawn particular attention because of their wide antimicrobial activity spectrum. However, controversial information on AgNPs toxicity limited their use in oral infections. Therefore, the aim of the present study was to evaluate the antibacterial activities against a panel of oral pathogenic bacteria and bacterial biofilms together with potential cytotoxic effects on human gingival fibroblasts of $10 \mathrm{~nm}$ AgNPs: non-functionalized - uncapped (AgNPs-UC) as well as surface-functionalized with capping agent: lipoic acid (AgNPs-LA), polyethylene glycol (AgNPs-PEG) or tannic acid (AgNPs-TA) using silver nitrate $\left(\mathrm{AgNO}_{3}\right)$ as control.

Methods: The interaction of AgNPs with human gingival fibroblast cells (HGF-1) was evaluated using the mitochondrial metabolic potential assay (MTT). Antimicrobial activity of AgNPs was tested against anaerobic Gram-positive and Gram-negative bacteria isolated from patients with oral cavity and respiratory tract infections, and selected aerobic Staphylococci strains. Minimal inhibitory concentration (MIC) values were determined by the agar dilution method for anaerobic bacteria or broth microdilution method for reference Staphylococci strains and Streptococcus mutans. These strains were also used for antibiofilm activity of AgNPs.

Results: The highest antimicrobial activities at nontoxic concentrations were observed for the uncapped AgNPs and the AgNPs capped with LA. It was found that AgNPs-LA and AgNPs-PEG demonstrated lower cytotoxicity as compared with the AgNPs-TA or AgNPs-UC in the gingival fibroblast model. All of the tested nanoparticles proved less toxic and demonstrated wider spectrum of antimicrobial activities than $\mathrm{AgNO}_{3}$ solution. Additionally, AgNPs-LA eradicated Staphylococcus epidermidis and Streptococcus mutans 1-day biofilm at concentration nontoxic to oral cells.

Conclusions: Our results proved that a capping agent had significant influence on the antibacterial, antibiofilm activity and cytotoxicity of AgNPs.

Clinical significance: This study highlighted potential usefulness of AgNPs against oral anaerobic Gram-positive and Gram-negative bacterial infections and aerobic Staphylococci strains provided that pharmacological activity and risk assessment are carefully performed.
\end{abstract}

Key words: silver nanoparticles; capping agent; human gingival fibroblasts; antibacterial activity; antibiofilm activity; cytotoxicity 


\section{Introduction}

For centuries silver has been used all over the world in order to prevent microbial infections. It has been effective against both aerobic and anaerobic bacteria for treatment of numerous infectious conditions in medicine and dentistry, very often with striking success [1]. Different compounds of silver and silver derivatives have been used as antimicrobial agents [2,3,4]. Nowadays, rapid development of nanotechnology has brought nano scale silver particles as a useful tool for dental practice [5]. Nanoparticles are defined as particles sizing between 1 and $100 \mathrm{~nm}$, and displaying properties that are not found in the same material in bulk [6,7]. The antimicrobial activity of AgNPs seems to be a function of the surface area to effectively interact with a certain microorganism. In general, large surface area of nanoparticles enhances the interaction with microbes and results in a wide spectrum of antimicrobial activities [8,9,10]. Interestingly, AgNPs' antibacterial activity was also observed for antibiotic resistant microorganisms $[8,10]$. Moreover, a combination of antibiotics with AgNPs was shown to exert synergistic effects $[11,12,13]$. For example, Strydom et al. [14] demonstrated that modification of silver sulfadiazine using dendrimers increased the antibacterial efficacy. All the above-mentioned properties of AgNPs contribute to the fact that they are being used more eagerly in dental practice to prevent against bacterial adhesion, growth and biofilm formation in oral surgery, implantology and anti-cavity products [5]. It has been detected that bone cements modified with AgNPs significantly reduced biofilm formation on the surface of the cement [15]. 100-nm spherical AgNPs at concentration of $20 \mu \mathrm{g} / \mathrm{mL}$ were effective in improving the clinical outcome and elimination of bacterial infection in periodontal pockets [16].

Nowadays, the spread of multi-drug resistant bacterial strains is a growing health [17]. Despite great improvement in oral health, dental caries and periodontal diseases are still among the most problematic infectious diseases to deal with in dental practice [18,19]. Moreover, frequently released reports indicate the role of biofilm production in bacterial pathogenicity. Biofilm can be defined as multicellular, sessile microbial community that represents the basic living form of most microorganisms. This highly specialized three-dimensional structure is characterized by strong resistance to antibiotics. It has been stated that over $80 \%$ of chronic infections are related to the presence of biofilm $[20,21]$. Bacteria of oral cavity environment, and specifically oral biofilms can enter the bloodstream, thereby causing many systemic diseases such as diabetes mellitus, cardiovascular diseases, rheumatoid arthritis, pneumonia and pre-term births [22]. Thus, taking good care of oral health is important not only to prevent local pathology but also to maintain general health.

It has to be emphasized that, AgNPs used in dentistry $[16,23]$ are in contact not only with the teeth but also with other oral cavity tissues and cells, which are not intended to be exposed to AgNPs. Thus, despite the unquestionable benefits of using AgNPs to protect against bacterial infections and disease, there are serious health concerns that must be addressed in order for the nanoparticles to comply with safety requirements [5,24]. Many studies indicated AgNPs-induced cytotoxicity in various types of human cells and tissues, including the oral cavity $[5,25,26,27,28]$. The question then arises: are AgNPs nontoxic to human cells at bactericidal concentrations? It should be emphasized that several factors influence the ability of nanometal to cause biological effects, such as the size, solubility, shape, surface charge and area as well as capping agents, being important determinants of pharmacological activity and toxicity $[25,29]$. Taking it all together, it seemed of clinical importance to investigate the relationship between the biological activity, and specifically: antimicrobial properties, cytotoxicity and surface functionalization of AgNPs. Therefore, in the present study we evaluated antimicrobial activity against a panel of anaerobic Gram-positive and Gram-negative bacteria isolated from patients with oral cavity and respiratory tract infections. In addition to that, activity against Staphylococci strains and Streptococcus mutans as well as biofilm formed by the bacteria was investigated. A potential cytotoxic effect of AgNPs on human gingival fibroblast cells was analyzed using a cell culture experimental setup. The experimental model was based on 10-nm seized AgNPs which were capped with three different agents of interest, i.e. polyethylene glycol, lipoic acid and tannic acid as well as uncapped AgNPs.

\section{Materials and Methods}

\section{Characterization of AgNPs}

AgNPs, $10 \mathrm{~nm}$ in seize: capped with LA, PEG and TA, water dispersed were obtained from Nanocomposix Europe; AgNPs $10 \mathrm{~nm}$ : uncapped, water dispersed - US Research Nanomaterials (Houston, TX, USA). $\mathrm{AgNO}_{3}$ was obtained from Sigma-Aldrich (Poland).

Characterization of AgNPs was performed by the manufacturer, according to good laboratory practice [30]. The size of AgNPs was measured using JEOL 1010 transmission electron microscope (TEM), mass concentration - Thermo Fisher $X$ Series 2 
ICP-MS, spectral properties - Agilent 8453 UV-Visible Spectrometer, zeta potential and hydrodynamic diameter - Malvern Zetasizer nano ZS. Measurement of AgNPs-UC size and size distribution was performed by JEM 1200 EXII transmission electron microscope (JEOL, Japan) at an operational voltage of $200 \mathrm{kV}$. For TEM measurements, a drop of the solution of AgNPs was placed on a carbon-coated copper grid and allowed to dry to record TEM images. Particle size distribution was obtained from a histogram considering more than 300 particles measured using multiple TEM micrographs. Additionally, measurements of zeta potential and hydrodynamic diameter by Malvern Zetasizer nano ZS (Malvern Instruments, Malvern, UK) were taken six times for all tested AgNPs at concentration 20 $\mu \mathrm{g} / \mathrm{mL}$ in serum-free (SF) culture medium at room temperature.

\section{Cell culture}

A HGF-1 cell line was obtained from the American Type Culture Collection (ATCC-HBT-55) and maintained as a monolayer culture in $\mathrm{T}-75 \mathrm{~cm}^{2}$ tissue culture flasks. The cells were grown in Dulbecco's Modified Eagle's Medium (Sigma Aldrich), a high glucose medium $(4.5 \mathrm{~g} / \mathrm{L})$ containing sodium pyruvate $(110 \mathrm{mg} / \mathrm{L})$, and supplemented with $10 \%$ fetal bovine serum, $6 \mu \mathrm{g} / \mathrm{mL}$ penicillin-G, and 10 $\mu \mathrm{g} / \mathrm{mL}$ streptomycin. Cells were cultured at $37^{\circ} \mathrm{C}$ in a humidified atmosphere of $95 \% \mathrm{O}_{2}, 5 \% \mathrm{CO}_{2}$. When confluent, cells were detached enzymatically with trypsin-EDTA and sub-cultured into a new cell culture flask. The medium was replaced every 2 days.

\section{Cell exposure to AgNPs}

The concentrations of AgNPs or $\mathrm{AgNO}_{3}(5,10$, $20,40,60,100 \mu \mathrm{g} / \mathrm{mL}$ ) were prepared ex tempore in serum-free cell culture medium (DMEM). Immediately before use, NPs solutions were shaken for 1 minute, following the manufacturer's instruction, to prevent aggregation. The solutions of AgNPs and $\mathrm{AgNO}_{3}$ were filtered through a $0.22 \mu \mathrm{m}$ membrane filter. Controls were prepared with an equivalent volume of culture media without AgNPs or $\mathrm{AgNO}_{3}$.

\section{Cell cytotoxicity evaluation by MTT assay}

Cell cytotoxicity was determined by MTT assay evaluated mitochondrial activity (corresponding to cell growth and death rate). HGF-1 cells were seeded in triplicate at a density of $10^{4}$ cells $/ 100 \mu \mathrm{L}$ of cell culture medium into a 96-well microplate. After 48 hrs, cells were exposed to different concentrations AgNPs or $\mathrm{AgNO}_{3}$ as indicated above for $24 \mathrm{~h}$. The assay was performed by adding a mix of optimized dye solution to the culture wells. Absorbance was recorded at $570 \mathrm{~nm}$ (FLUOstar OPTIMA). Results from the treatment groups were calculated as percentage of control values (untreated cells) according to the following equation: $\%$ viability = (experimental absorbance [abs] $570 \mathrm{~nm}$ of exposed cells - background experimental absorbance [abs] 570 $\mathrm{nm}) \times 100 \% / \mathrm{abs} 570 \mathrm{~nm}$ of unexposed cells. Absorbance values were corrected for background (NPs blank used for each concentration).

\section{Antimicrobial and antibiofilm activity}

The effect of AgNPs and $\mathrm{AgNO}_{3}$ on antimicrobial activity against 27 strains of anaerobic bacteria and 6 reference strains was investigated.

The bacterial strains were isolated from patients with oral cavity and respiratory tract infections. The following anaerobes were tested: Actinomyces (1 strain), Bacteroides (4 strains), Bifidobacterium (1 strain), Finegoldia (2 strains) Fusobacterium (4 strains), Parabacteroides (1 strain), Parvimonas (2 strains) Peptostreptococcus (1 strain) Porphyromonas (3 strains), Prevotella (5 strains), Propionibacterium (2 strains) Tannerella (1 strain) and reference strains from genus: Bacteroides fragilis ATCC 25285, Bifidobacterium breve ATCC 15700, Fusobacterium nucleatum ATCC 25585, Peptostreptococcus anaerobius ATCC 25286, Porphyromonas levii ATCC 29147 and Prevotella loescheii ATCC 15930. Isolated strains of anaerobic bacteria were identified in accordance with the current microbial analysis principles [31,32]. The classification of anaerobes was based on morphological, physiological and biochemical tests (API $20 \mathrm{~A}$, bioMerieux). Analysis of conversion of glucose into $C$ 1 to $C 6$ fatty acids, succinic acid, fumaric acid and lactic acid were determined using gas chromatography, and the ability of a colony to produce fluorescence was observed at ultra-violet radiation spectrum (UV) [32,33]. Clinical trials have been authorized by the Bioethics Committee of the Medical University of Gdansk, no. NKBBN/161/2014. The susceptibility of anaerobic bacteria to AgNPs and $\mathrm{AgNO}_{3}$ was determined by means of plate dilution methods in Brucella agar, supplemented with 5\% defibrinated sheep blood, menadione and hemin, and the minimal inhibitory concentration (MIC) was read. The following AgNPs concentrations were used: 100, $80,40,20,10$ and $5.0 \mu \mathrm{g} / \mathrm{mL}$. Adequate concentrations were prepared in Brucella agar [34]. Suspensions of bacterial strains containing $10^{5} \mathrm{CFU}$ per spot were inoculated onto agar surface with Steers replicator. Plates were incubated under anaerobic conditions (anaerobic jars) in the presence of $10 \% \mathrm{CO}_{2}, 10 \% \mathrm{H}_{2}$ and $80 \% \mathrm{~N}_{2}$, palladic catalist and anaerobiosis indicator, at $37^{\circ} \mathrm{C}$ for 48 hours. MIC was defined as the lowest concentration of $\mathrm{AgNPs}$ or $\mathrm{AgNO}_{3}$ that inhibited 
growth of the anaerobic bacteria.

Antibiofilm activity of tested AgNPs was conducted on a biofilm producing by reference strains of bacteria: Staphylococcus aureus ATCC 25932, S. aureus ATCC 6538, Staphylococcus aureus ATCC 6538/P, Staphylococcus epidermidis ATCC 14990 and Streptococcus mutans ATCC 29175. MIC for these strains was determined by broth microdilution method with Mueller Hinton broth according to CLSI (Clinical and Laboratory Standards Institute) recommendations. Polypropylene 96-well plates with bacteria at initial inoculums of $5 \times 10^{5} \mathrm{CFU} / \mathrm{mL}$ exposed to tested compounds $(0.3125-100 \mu \mathrm{g} / \mathrm{mL})$ were incubated at $37^{\circ} \mathrm{C}$ for $24 \mathrm{~h}$. MIC was taken as the lowest drug concentration at which visible growth of microbes was inhibited. Determination of minimal biofilm eradicating concentration (MBEC) was performed on 96-well polystyryne plates using resazurin (7-hydroxy-3H-phenoxazin-3-one 10-oxide) as a cell-viability reagent and Mueller Hinton Broth as a medium. Biofilms were cultured on polystyrene plates for 1, 2 and 3 days. Each day bacteria-containing wells were washed with Phosphate-buffered saline for three times in order to rinse free floating bacteria. Subsequently the fresh medium was added and the biofilms were exposed to ranging concentrations of tested compounds (5 - 100 $\mu \mathrm{g} / \mathrm{mL})$. After a 24-h incubation, resazurin was added and the MBEC was read. All experiments were performed in triplicate.

\section{Statistical analysis}

The experimental results were expressed as mean \pm SD for triplicate determination of 3-4 separate experiments. The results were analyzed using one-way ANOVA and Tukey's post hoc test and p value $<0.05$ was considered statistically significant.

\section{Results}

\section{Characterization of AgNPs}

An accurate and careful physical and chemical characterization of nanoparticles prior to any biological tests is of crucial importance [35]. Both chemical and physical properties of tested AgNPs are presented in Table 1 . We tested commercially available spherical AgNPs, either uncoated or coated with LA, PEG and TA, sized: $11.2 \pm 2.1 \mathrm{~nm}$; $9.5 \pm 1.9$ $\mathrm{nm} ; 9.8 \pm 2.0 \mathrm{~nm} ; 10.0 \pm 1.8 \mathrm{~nm}$, respectively. The morphology and the size distribution histograms of AgNPs are illustrated in Figure 1 A-D.

The TEM images and TEM size distribution histogram show a well-monodispersed spherical shape in the size range of 7-17 nm, 7-15 nm, 6-21 nm and 7-15 nm for AgNPs-LA, AgNPs-PEG, AgNPs-TA and AgNPs-UC, respectively. As expected, the hydrodynamic diameters of NPs presented in Table 1 were larger than the size estimated by TEM; this observation is consistent with the literature [36]. The zeta potential measured for AgNPs-LA, AgNPs-TA and AgNPs-UC was $-28.6 \mathrm{mV}$ and $-34.9 \mathrm{mV}$ and -33.9 $\mathrm{mV}$, respectively, and indicated good stability of NPs in cell culture medium [37]. The highest tendency to aggregate in SF culture medium was observed for AgNPs-PEG with the zeta potential value of $-10 \pm 10 \mathrm{mV}$. Indeed, for these NPs was found the biggest differences between the hydrodynamic diameter and diameter obtained from TEM micrographs: $9.8 \mathrm{~nm}$ and $30.3 \mathrm{~nm}$, respectively (Table 1).

\section{Cytotoxicity of AgNPs evaluation}

We evaluated the impact of AgNPs (at concentration: $5,10,20,40,60,100 \mu \mathrm{g} / \mathrm{mL}$ ) on the viability of human gingival fibroblast cells (HGF-1) after $24 \mathrm{~h}$ of incubation (Figure 2). HGF-1 cell line is a common in vitro model to investigate the interaction between xenobiotics and gingival fibroblast cells in vitro $[25,38,39]$.

Table 1. AgNPs characterization.

\begin{tabular}{|c|c|c|c|c|}
\hline Characterization & AgNPs-LA & AgNPs-PEG & AgNPs-TA & AgNPs-UC* \\
\hline Diameter & $9.5 \pm 1.9 \mathrm{~nm}$ & $9.8 \pm 2.0 \mathrm{~nm}$ & $10.0 \pm 1.8 \mathrm{~nm}$ & $11.2 \pm 2.1 \mathrm{~nm}$ \\
\hline Coefficient of Variation & $19.9 \%$ & $20.0 \%$ & $18.4 \%$ & $19.6 \%$ \\
\hline Surface Area & $55.96 \mathrm{~m}^{2} / \mathrm{g}$ & $53.5 \mathrm{~m}^{2} / \mathrm{g}$ & $53.4 \mathrm{~m}^{2} / \mathrm{g}$ & $54.8 \mathrm{~m}^{2} / \mathrm{g}$ \\
\hline Density (Ag) & $0.99 \mathrm{mg} / \mathrm{mL}$ & $1.10 \mathrm{mg} / \mathrm{mL}$ & $0.91 \mathrm{mg} / \mathrm{mL}$ & $50 \mathrm{mg} / \mathrm{mL}^{\neq}$ \\
\hline Particle Concentration & $2.1 \mathrm{E}+14$ particles $/ \mathrm{mL}$ & $2.1 \mathrm{E}+14$ particles $/ \mathrm{mL}$ & $1.7 \mathrm{E}+14$ particles $/ \mathrm{mL}$ & NA \\
\hline $\begin{array}{l}\text { Hydrodynamic Diameter } \\
\text { in SF cell culture medium }\end{array}$ & $22.1 \mathrm{~nm}$ & $30.3 \mathrm{~nm}$ & $16.1 \mathrm{~nm}$ & $18.6 \mathrm{~nm}^{*}$ \\
\hline $\begin{array}{l}\text { Zeta Potential } \\
\text { in SF cell culture medium }\end{array}$ & $-28.6 \mathrm{mV}$ & $-10 \pm 10 \mathrm{mV}$ & $-34.9 \mathrm{mV}$ & $-33.9 \mathrm{mV}^{*}$ \\
\hline Particle Surface & Lipoic Acid & mPEG $5 \mathrm{kDa}$ & Tannic Acid & --- \\
\hline
\end{tabular}


A
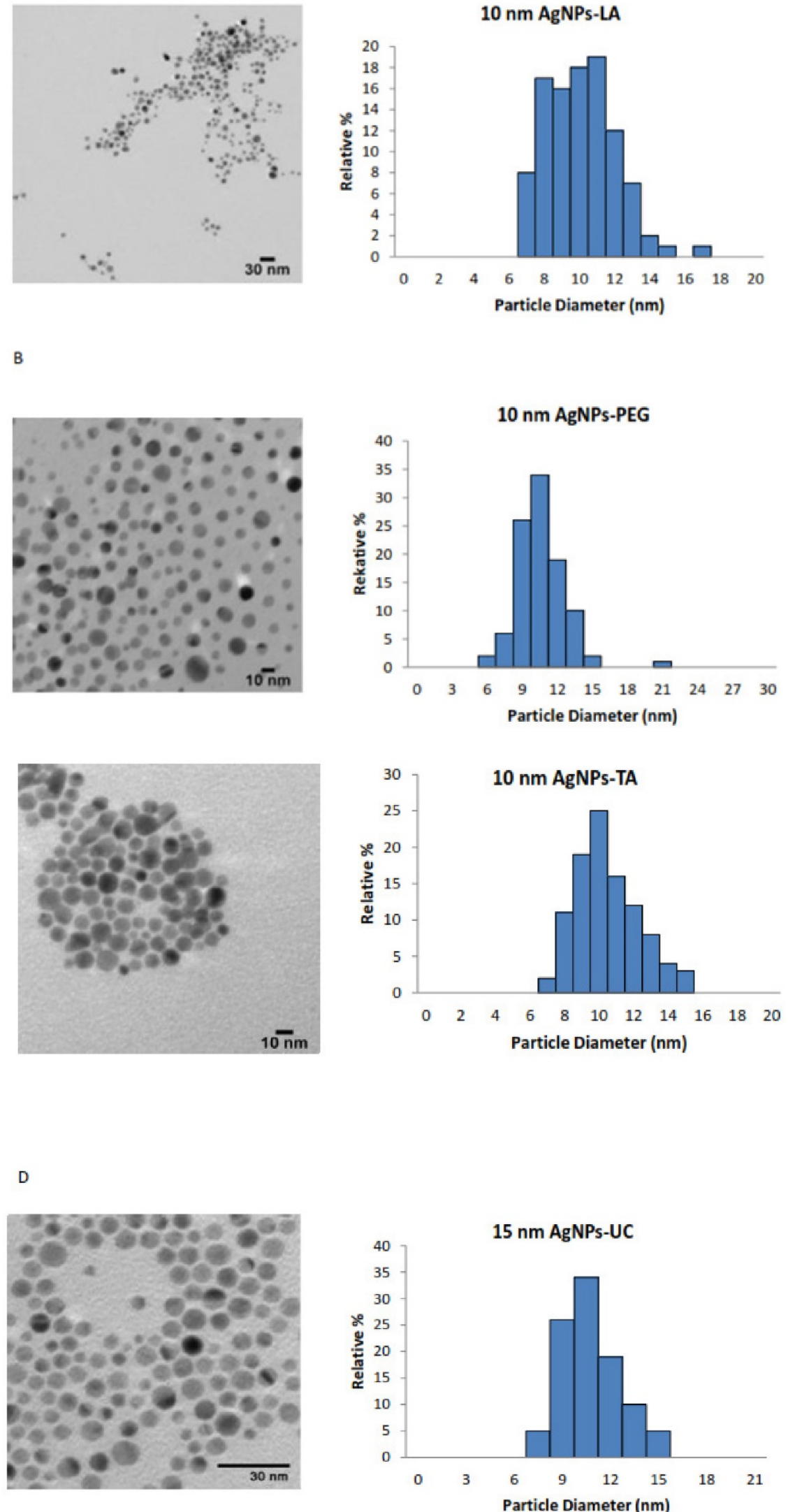

Figure 1. Characterization of AgNPs using transmission electron microscopy (TEM). The representative microscopy images show shape of AgNPs; the histograms illustrate the range of particle size distribution obtained from TEM measurements of more than 300 particles: (A) AgNPs capped with lipoic acid, (B) AgNPs capped with polyethylene glycol, (C) AgNPs capped with tannic acid and (D) uncapped AgNPs. 


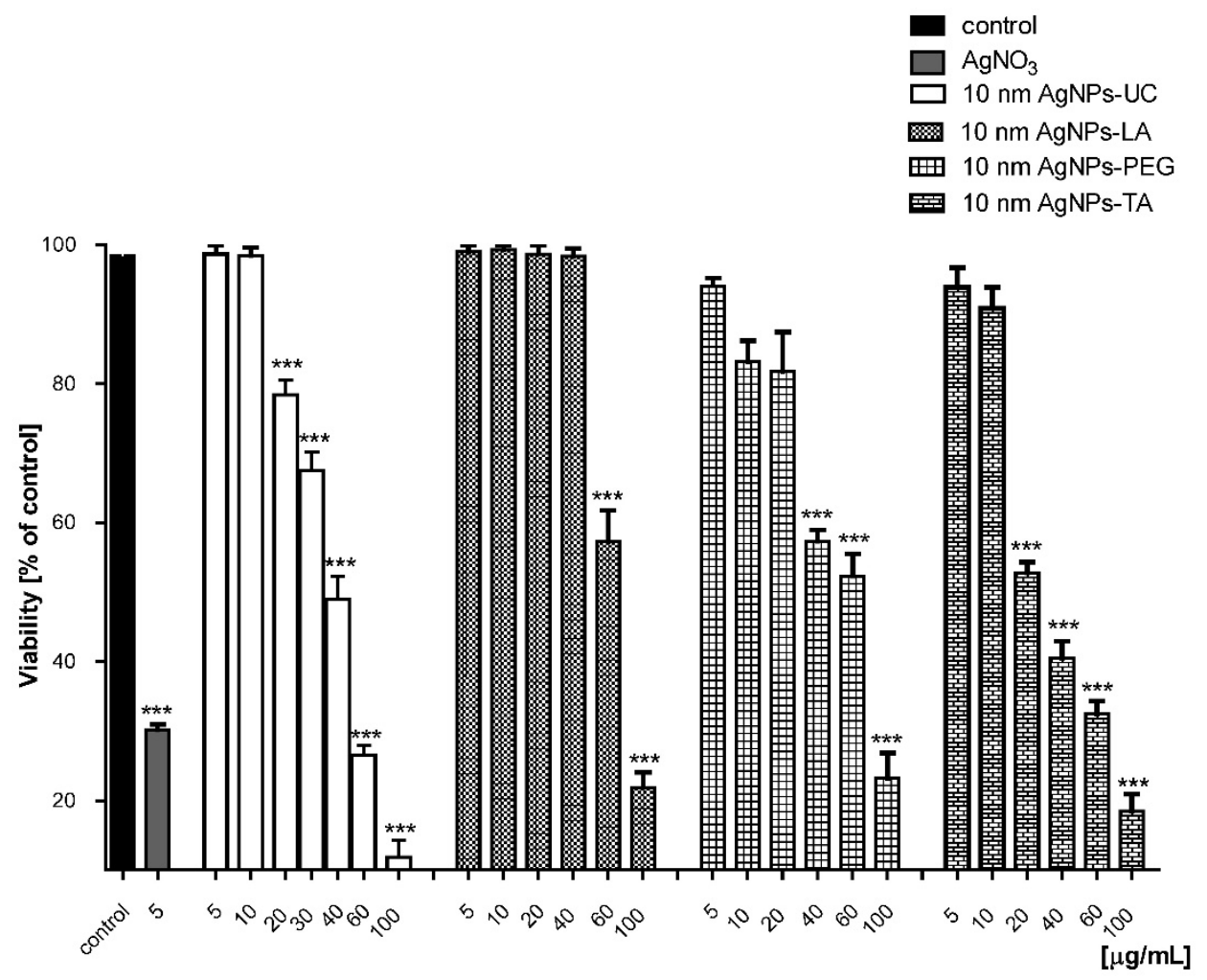

Figure 2. AgNPs-induced decrease in cell viability. The $24 \mathrm{~h}$ treatments of cells with AgNPs decreased HGF1 cell viability. Data are mean \pm SD of 3-4 separate determinations. ${ }^{* * *} p<0.001$ as compared with control.

We found that AgNPs induced cell death in a concentration dependent-manner. AgNPs-UC did not cause any toxicity at concentrations up to $10 \mu \mathrm{g} / \mathrm{mL}$; AgNPs-LA - up to $40 \mu \mathrm{g} / \mathrm{mL}$; AgNPs-PEG; up to - 20 $\mu \mathrm{g} / \mathrm{mL} ;$ AgNPs-TA - $10 \mu \mathrm{g} / \mathrm{mL} . \mathrm{AgNO}_{3}$, at all used concentrations significantly decreased cell viability (data shown only for $5 \mu \mathrm{g} / \mathrm{mL}$ ).

\section{Antibacterial activity of AgNPs}

AgNPs-LA at concentrations $\leq 5-40 \mu \mathrm{g} / \mathrm{mL}$ (nontoxic) inhibited growth of 19 (70\%) bacterial strains, and specifically 10 (55\%) Gram-negative and all $(100 \%)$ of the Gram-positive bacterial strains (Table 2A and Table 2B). AgNPs-PEG at investigated concentrations (MIC $\leq 5-100 \mu \mathrm{g} / \mathrm{mL}$ ) inhibited growth of $96 \%$ strains of tested anaerobic bacteria. However, AgNPs-PEG at concentrations 5-20 $\mu \mathrm{g} / \mathrm{mL}$ (nontoxic to gingival fibroblast cells) inhibited growth of $8(89 \%)$ Gram-positive bacterial strains and $5(28 \%)$ strains of Gram-negative bacteria (Table 2A and Table 2B). AgNPs-TA at concentrations $5-10$ $\mu \mathrm{g} / \mathrm{mL}$ (nontoxic) inhibited only $1(5 \%)$ strain of Gramm-negative bacteria of the Prevotella levii genus and $7(78 \%)$ strains of the Gram-negative anaerobes (Table 2A and Table 2B). The remaining strains required a higher concentrations of AgNPs-TA with an MIC range of $20-\geq 100 \mu \mathrm{g} / \mathrm{mL}$. AgNPs-UC, at concentrations $\leq 5-10 \mu \mathrm{g} / \mathrm{mL}$ inhibited growth of 11
(61\%) strains of Gram-negative bacteria and all (100\%) of the investigated strains of Gram-positive bacteria (Table 2A and Table 2B). Among the most susceptible anaerobes were strains of Gram-positive cocci and Gram-positive rods. $\mathrm{AgNO}_{3}$, used as control at concentrations $\leq 5 \mu \mathrm{g} / \mathrm{mL}$ inhibited growth of 2 $(7.5 \%)$ tested strains. $\mathrm{AgNO}_{3}$ inhibited growth of the majority of anaerobic bacteria at concentrations $\geq 100$ $\mu \mathrm{g} / \mathrm{mL}$ (Table 2A and Table 2B).

All tested nanoparticles inhibited growth of examined Staphylococcus strains and Streptococcus mutans at nontoxic concentrations (Table 3).

However, the activity against bacterial 2- and 3-days biofilm formed by these strains was not so effective, and concentrations $\geq 100 \mu \mathrm{g} / \mathrm{mL}$ were needed (data not shown). However, AgNPs-LA eradicated Staphylococcus epidermidis and Streptococcus mutans 1-day biofilm at concentrations $20 \mu \mathrm{g} / \mathrm{mL}$ and $40 \mu \mathrm{g} / \mathrm{mL}$, respectively which were proven nontoxic to human gingival fibroblast cells (Figure 3). AgNPs-PEG were effective against Staphylococcus epidermidis 1-day biofilm at concentration $80 \mu \mathrm{g} / \mathrm{mL}$ and AgNPs-UC - against Streptococcus mutans 1-day biofilm at concentrations $40 \mu \mathrm{g} / \mathrm{mL}$, which significantly decreased the viability of gingival fibroblast cells (Figure 3). 
Table 2A. Susceptibility of Gram-negative anaerobic bacteria to $\mathrm{AgNPs}$ and $\mathrm{AgNO}_{3}$

\begin{tabular}{|c|c|c|c|c|c|c|c|c|c|c|c|c|c|c|c|c|c|c|c|c|c|c|c|c|c|c|c|c|c|c|c|}
\hline \multirow[b]{3}{*}{ Microorganisms } & \multirow{3}{*}{ 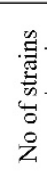 } & \multicolumn{30}{|c|}{ Minimal inhibitory concentration (MIC) in $\mu \mathrm{g} / \mathrm{mL}$, } \\
\hline & & \multicolumn{6}{|c|}{ AgNPs-LA } & \multicolumn{7}{|c|}{ AgNPs-PEG } & \multicolumn{5}{|c|}{ AgNPs-TA } & \multicolumn{7}{|c|}{ AgNPs-UC } & \multicolumn{5}{|c|}{$\mathrm{AgNO}_{3}$} \\
\hline & & $\frac{\stackrel{8}{8}}{\Delta}$ & $\stackrel{\circ}{\mathscr{\infty}}$ & 官 & $\stackrel{\circ}{8}$ & $\stackrel{8}{9}$ & $\stackrel{\circ}{i n}$ & 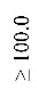 & $\dot{0}$ & $\stackrel{8}{+}$ & $\stackrel{\circ}{\stackrel{1}{1}}$ & $\stackrel{\varrho}{\varrho}$ & $\stackrel{\circ}{\dot{v}}$ & $\frac{\stackrel{8}{\Xi}}{\wedge}$ & $\stackrel{\leftrightarrow}{\&}$ & $\stackrel{8}{g}$ & $\stackrel{8}{8}$ & $\stackrel{\varrho}{\varrho}$ & $\begin{array}{c}\stackrel{\rho}{r} \\
\dot{v}\end{array}$ & $\frac{\wp}{8}$ & $\stackrel{\circ}{\mathscr{\infty}}$ & $\ddot{8}$ & $\stackrel{8}{8}$ & $\stackrel{\varrho}{\varrho}$ & $\begin{array}{c}\stackrel{\leftrightarrow}{n} \\
\dot{v}\end{array}$ & $\frac{\Theta}{\stackrel{8}{S}}$ & $\stackrel{\circ}{\circ}$ & $\ddot{q}$ & $\stackrel{\ddot{Z}}{\circ}$ & $\stackrel{\circ}{9}$ & 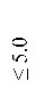 \\
\hline $\begin{array}{l}\text { Porphyromonas } \\
\text { asaccharolytica }\end{array}$ & 1 & & & & & & 1 & & & & 1 & & & & & 1 & & & & & & & & & 1 & & & & 1 & & \\
\hline Porphyromonas gingivalis & 1 & & & & 1 & & & & & & 1 & & & & & 1 & & & & & & & & & 1 & & & & 1 & & \\
\hline Porphyromonas levii & 1 & & & & 1 & & & & & & 1 & & & & & & & 1 & & & & & & 1 & & & & & 1 & & \\
\hline Prevotella buccalis & 2 & 2 & & & & & & 2 & & & & & & 1 & 1 & & & & & & & 1 & 1 & & & 1 & 1 & & & & \\
\hline Prevotella intermedia & 2 & & & & 1 & 1 & & & & & 2 & & & & & 2 & & & & & & & & & 2 & 2 & & & & & \\
\hline Prevotella loescheii & 1 & & & & & 1 & & & & 1 & & & & & & 1 & & & & & & & & & 1 & 1 & & & & & \\
\hline Tannerella forsythia & 1 & & & & 1 & & & & & 1 & & & & & & 1 & & & & & & & & 1 & & 1 & & & & & \\
\hline liusobacterium nucleatum & 2 & & & 2 & & & & & & 2 & & & & & 1 & 1 & & & & & & & 1 & 1 & & 2 & & & & & \\
\hline l'usobacterium & & & & & & & & & & & & & & & & & & & & & & & & & 2 & 2 & & & & & \\
\hline necrophorum & 2 & 1 & & 1 & & & & & & 2 & & & & 1 & & 1 & & & & & & & & & & & & & & & \\
\hline Parabacteroides distasonis & 1 & & 1 & & & & & & & 1 & & & & & 1 & & & & & & & & & & 1 & 1 & & & & & \\
\hline Bacteroides fragilis & 1 & & 1 & & & & & & 1 & & & & & 1 & & & & & & 1 & & & & & & 1 & & & & & \\
\hline Bactcroides uniformis & 1 & 1 & & & & & & 1 & & & & & & 1 & & & & & & 1 & & & & & & 1 & & & & & \\
\hline Bacteroides ureolyticus & 2 & 2 & & & & & & & & 2 & & & & & 1 & 1 & & & & & & 2 & & & & 2 & & & & & \\
\hline $\begin{array}{l}\text { Gram-negative rods } \\
\text { total }\end{array}$ & 18 & 6 & 2 & 3 & 4 & 2 & 1 & 3 & 1 & 9 & 5 & & & 4 & 4 & 9 & & 1 & & 2 & & 3 & 2 & 3 & 8 & 14 & 1 & & 3 & & \\
\hline Reference strains: & & & & & & & & & & & & & & & & & & & & & & & & & & & & & & & \\
\hline P. levii ATCC 29147 & 1 & & & & & & 1 & & & & 1 & & & & & & 1 & & & & & 1 & & & & & & & 1 & & \\
\hline P.loescheii ATCC 15930 & 1 & 1 & & & & & & & & & 1 & & & & & & 1 & & & & & & & & 1 & 1 & & & & & \\
\hline F.nucleatum $\triangle \mathrm{TCC} 25586$ & 1 & & & 1 & & & & & & 1 & & & & & & 1 & & & & & & & 1 & & & 1 & & & & & \\
\hline B.fragilis $\triangle \mathrm{TCC} 25285$ & 1 & 1 & & & & & 1 & & & & & & 1 & & & & & & & 1 & & & & & & 1 & & & & & \\
\hline
\end{tabular}

Table 2B. Susceptibility of Gram-positive anaerobic bacteria to $\mathrm{AgNPs}$ and $\mathrm{AgNO}_{3}$.

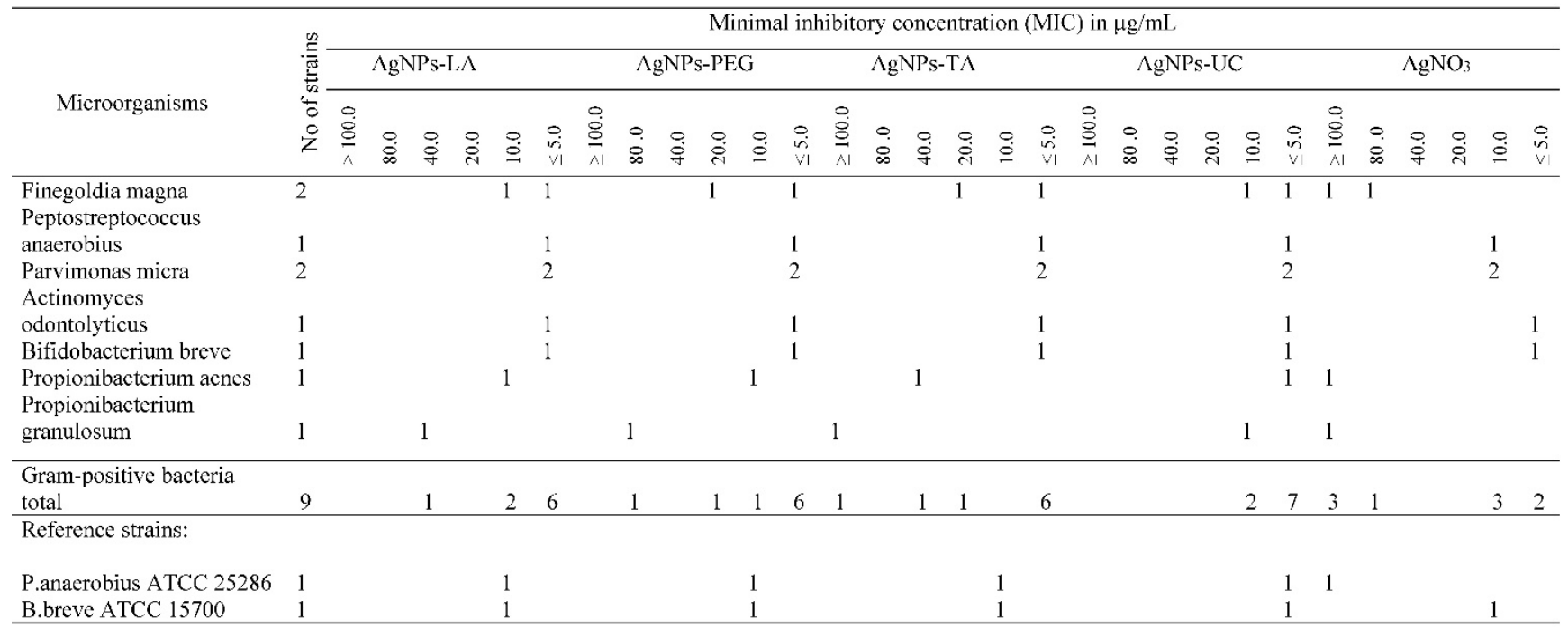

Table 3. Susceptibility of Staphylococcus strains and Streptococcus mutans to AgNPs.

\begin{tabular}{|c|c|c|c|c|c|}
\hline \multirow[b]{2}{*}{ Nanoparticles } & \multicolumn{3}{|c|}{ Minimal inhibitory concentration ( MIC) in $\mu \mathrm{g} / \mathrm{mL}$} & \multirow[b]{2}{*}{ S. epidermidis } & \multirow[b]{2}{*}{ S. mutans } \\
\hline & S. aureus & S. aureus & S. aureus & & \\
\hline & ATCC & ATCC & ATCC & ATCC & ATCC \\
\hline & 25923 & 6538 & $6538 / \mathrm{P}$ & 14990 & 29175 \\
\hline AgNPs-LA & 5.0 & 2.5 & 5.0 & 5.0 & 5.0 \\
\hline AgNPs-PEG & 2.5 & 5.0 & 10.0 & 0.625 & 10 \\
\hline AgNPs-TA & 5.0 & 5.0 & 10.0 & 1.25 & 10 \\
\hline AgNPs-UC & 2.5 & 2.5 & 10.0 & 0.3125 & 10 \\
\hline
\end{tabular}




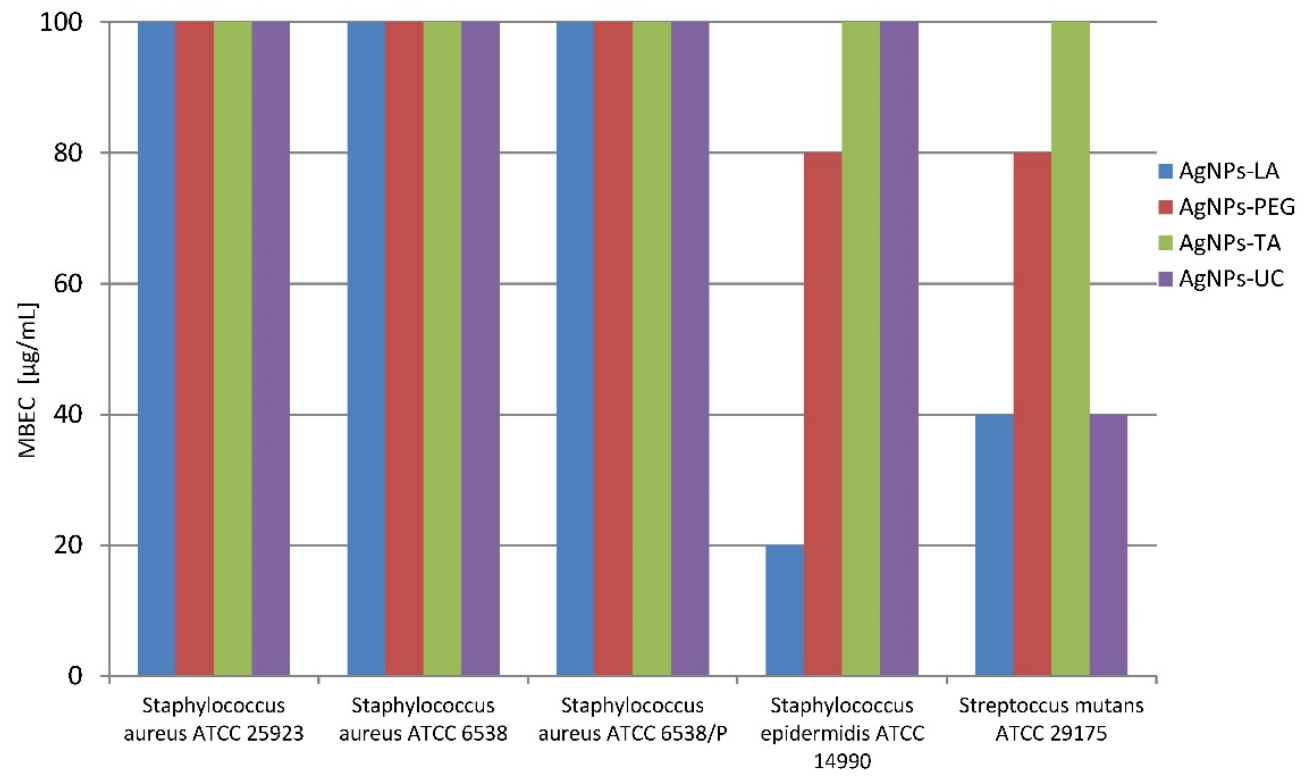

Figure 3. Susceptibility of 1-day biofilm (MBEC) formed by reference strains bacteria to AgNPs $(\mu g / \mathrm{mL})$

\section{Discussion}

In the present study, we evaluated the effect of surface functionalization of AgNPs with the size of 10 $\mathrm{nm}$ on antibacterial activity and cytotoxicity. We have previously observed AgNPs-induced oxidative damage and inflammatory lesion in human gingival fibroblast cells [25]. Importantly, we found that the cytotoxicity of AgNPs was enhanced by co-exposure with sodium fluoride - the latter widely used in dental medicine. However, due to a wide spectrum of antimicrobial activity it seemed interesting to continue the study in order to find factors which can minimize cytotoxicity without reducing antimicrobial activity of the AgNPs. Therefore, we tested commercially available well-characterized AgNPs both in ultrapure water and SF culture medium, with different capping agents keeping their size and shape the same. It was demonstrated that among many different factors, the capping agents played an important role in AgNPs interaction with bacterial cells and affected gingival fibroblast cytotoxicity $[40,41,42,43]$. However, it seemed necessary to evaluate antimicrobial activity of AgNPs as well as their potential cytotoxicity to human cells at the same time. We tested commercially available AgNPs, sized $10 \mathrm{~nm}$ : uncapped and capped with LA, PEG and TA. Their antibacterial activity and cytotoxicity were compared to $\mathrm{AgNO}_{3}$ as a silver containing compound which has been used in clinical practice for many years against oral pathogens that cause cavities, periodontitis and other oral cavity pathologies $[44,45]$. Interestingly, a solution of $25 \% \mathrm{AgNO}_{3}$ and $5 \% \mathrm{NaF}$ varnish have been accepted by most countries and approved by the Food and Drug Administration (FDA) as effective agents in prevention and treatment of early childhood caries [46]. PEG is one of the commonplace molecules used to functionalize the surface of metal NPs in order to improve stability and prevent uptake by the reticular endothelial system [47]. Tannic acid, is a plant derived polyphenolic compound, characterized as being harmless and environmentally friendly along with being a good reducing and stabilizing agent. Tannic acid is often used as a capping agent in applications where high particle concentrations are required [48]. Lipoic acid is a natural biomolecule consisting of five-membered cyclic disulphide tailing a short hydrocarbon chain on one end and a carboxylic group on the other. Lipoic acid has been shown to exhibit diverse biological effects ranging from anti-inflammatory to antioxidant protection [49].

Although recently AgNPs are more commonly used in oral medicine, there are some unclear risks associated with the exposure of the local cells and tissues to this kind of xenobiotic [25,50,51]. Thus, we evaluated the impact of AgNPs on the viability of human gingival fibroblast cells (HGF-1). Interestingly, we found that capped AgNPs-LA and AgNPs-PEG are less toxic than the uncapped ones showing similar effects as AgNPs-TA. The lowest cytotoxicity was observed for the AgNPs capped with LA. The differences in toxicity between all capped AgNPs clearly demonstrated that the capping agent is the one that influenced AgNPs toxicity. On the other hand, Gliga et al. [52] compared $10 \mathrm{~nm}$ citrate and $10 \mathrm{~nm}$ polivinylopirolidon (PVP) coated AgNPs and suggested that the size rather than a capping agent influenced 
AgNPs cytotoxicity to human lung cells. It was also demonstrated that certain nanoparticle capping agents may reduce the toxicity of nanoparticles $[41,42,53]$. $Y u$ et al. [53] showed that iron oxide nanoparticles, both dextran and PEG coated are significantly less toxic to endothelial cells as compared to uncoated NPs. Interestingly, DeBrosse et al. [54] demonstrated that surface functionalization of gold nanorods by TA resulted in a considerable degree of cytotoxicity as observed in the human keratinocyte cell line. It was proposed that cytotoxicity of AgNPs changes with surface potential of NPs, indicating that the positively charged ones are most biocompatible while the more negatively charged are the most toxic [55]. However, in our study the least cytotoxic AgNPs-LA as well as the most cytotoxic AgNPs-TA and AgNPs-UC had all highly negative zeta potential. In conclusion, our cytotoxicity evaluation study provides evidence that a nontoxic range of concentrations exists for the safe use of all tested AgNPs.

Next, we investigated the antimicrobial activity of tested AgNPs against the bacterial strains isolated from patients with infections of the oral cavity and respiratory tract. It should be emphasized that all the investigated AgNPs were more active against Gram-positive rather than Gram-negative anaerobes. Pettegrew et al. [56] presumed that AgNPs would interact quickly with "naked" peptides on the wall of Gram-positive bacteria but slowly with the cell wall covered with an extra lipopolysaccharide layer in Gram-negative bacteria. It was well documented that the carboxyl and phosphate groups on the cellular membrane of both Gram-positive and Gram-negative bacteria, provide a clear negative charge at physiological $\mathrm{pH}$ [57]. All of the AgNPs tested in our study exhibited negative zeta potential. Thus, a kind of electrostatic barrier could be formed between the negatively charged AgNPs and bacteria that limited cell-particle interactions reducing the antimicrobial activity [57]. Indeed, AgNPs with the highest negative zeta potential (coated with TA) at nontoxic concentrations inhibited only 7 strains of tested bacteria (1 strain of Gram-negative bacteria, 6 strains of Gram-positive bacteria). However, AgNPs with the lowest negative zeta potential (capped with PEG) did not exert the strongest antimicrobial effects. These results proved that a surface coating agent significantly influenced the antimicrobial activity of AgNPs. It was demonstrated that the capped AgNPs exhibited higher antibacterial activity than the uncoated AgNPs [58,59]. Jaiswal et al. [40] observed enhancement of antibacterial properties against Escherichia coli, Pseudomonas aeruginosa and Staphylococcus aureus using AgNPs capped with beta-cyclodextrin. However, our data did not demonstrate such simple relationship between capped and uncapped AgNPs, and their gingival fibroblast toxicity along with the antimicrobial activity. We found that both Gram-positive and Gram-negative anaerobic bacterial strains were most susceptible to AgNPs-UC and AgNPs-LA at nontoxic concentrations. Moreover, we observed that all strains, within the same concentration range (MIC 5.0 - $100.0 \mu \mathrm{g} / \mathrm{mL}$ ) were more susceptible to the tested AgNPs rather than to the reference solution of $\mathrm{AgNO}_{3}$. Interestingly enough, AgNPs-TA exerted the highest cytotoxic effect on the gingival fibroblast cells and the lowest antimicrobial activity at nontoxic concentration levels as compared to all other investigated AgNPs.

Importantly, many studies have also demonstrated a significant activity of AgNPs against bacterial biofilms. For example, Goswami et al. [60] investigated the 20-nm AgNPs mediated biofilm eradication, and detected inhibition of $89 \%$ for Staphylococcus aureus at $15 \mu \mathrm{g} / \mathrm{mL}$. It was also reported that AgNPs with size of $9.5 \mathrm{~nm}$ showed 2.3 $\log$ reduction of Streptococcus mutans biofilms at concentration of $100 \mu \mathrm{g} / \mathrm{mL}$. However, the cytotoxic effect upon human dermal fibroblasts was observed at concentrations $>10 \mu \mathrm{g} / \mathrm{mL}$ [61]. It should be noticed that bacterial biofilms can be up to 1000 times more resistant to antibiotics than planktonic cells $[62,63,64,65]$. Therefore, it was interesting to evaluate the activity of all tested AgNPs, first against oftentimes biofilm-forming oral cavity bacteria, such as: Staphylococcus aureus Staphylococcus epidermidis and Streptococcus mutans, and then against the biofilm formed by these strains. Streptococcus mutans belongs to the viridans group of oral streptococci and the main etiological agents of tooth decay [63]. Recently, it has been indicated that also Staphylococcus species, especially Staphylococcus epidermidis and Staphylococcus aureus, are frequently isolated from the oral cavity [64]. These bacteria are also associated with chronic wound infections and periodontitis [65]. Moreover, the use of antibiotics in case of periodontal disease may predispose to increase the number of Staphylococcus species in the oral cavity $[66,67,68]$. There are very different values of MIC reported for AgNPs against Staphylococcus or Streptococcus strains in the literature, most probably due to differences in the size, physicochemical properties, functionalization and methods of synthesis $[61,68]$. For example, an average MIC of $4.86 \mu \mathrm{g} / \mathrm{mL}$ was reported for $25 \mathrm{~nm}$ AgNPs against Streptococcus mutans [69]. Interestingly Espinosa-Cristóbal et al. [70] found much higher MIC against the same strain: $101.98 \mu \mathrm{g} / \mathrm{mL}, 145.64 \mu \mathrm{g} / \mathrm{mL}$, and $320.63 \mu \mathrm{g} / \mathrm{mL}$ for 
AgNPs with the size of $8.4 \mathrm{~nm}, 16.1 \mathrm{~nm}$, and $98 \mathrm{~nm}$, respectively. However, the main concern is whether or not the antibacterial efficient concentrations of AgNPs are nontoxic to human cells? In our study we have observed that all tested AgNPs exerted antimicrobial activities against Staphylococcus strains and Streptococcus mutans at nontoxic concentration.

It was also found that treatment with AgNPs at a concentration lower than $50 \mu \mathrm{g} / \mathrm{mL}$ inhibited biofilm formation by methicillin resistant Staphylococcus aureus and methicillin-resistant Staphylococcus epidermidis. Kalishwaralal et al. [71] demonstrated that treatment of Staphylococcus epidermidis with AgNPs at a concentration of $100 \mu \mathrm{M}$ resulted in more than $95 \%$ inhibition of biofilm formation. They suggested that this result opened new possibilities of alternative therapies in clinical practice. However, in our study considering gingival fibroblast cells nontoxic concentrations, only AgNPs-LA proved effective against Staphylococcus epidermidis and Streptococcus mutans 1-day biofilm, additionally indicating the capping agent-dependent antibiofilm activity of AgNPs. It was observed that AgNPs decreased Staphylococcus aureus biofilm activity by approximately $90 \%$ at concentration as low as 0.7 $\mu \mathrm{g} / \mathrm{mL}$ [72]. However, the size of AgNPs was $5 \mathrm{~nm}$ and it has been reported previously that NPs with the diameter below $10 \mathrm{~nm}$ are often cytotoxic to human cells $[25,52]$.

This is the first report to show the link between capping agent-dependent AgNPs toxicity to oral cavity cells and antibacterial activity against a panel of oral pathogenic bacteria and bacterial biofilm formed by Staphylococcus strains and Streptococcus mutans. Our results prove that a capping agent significantly modifies biological characteristics of AgNPs, and specifically affects the antibacterial and antibiofilm activity as well as cytotoxicity of AgNPs.

\section{Conclusion}

In conclusion, our work shows that AgNPs-LA and AgNPs-PEG exert the least cytotoxic effect against gingival fibroblasts as compared to AgNPs-UC. However, both AgNPs-UC and AgNPs-LA, at concentrations nontoxic to human gingival fibroblast cells, exert the strongest antimicrobial effect on the bacterial strains isolated from patients with infections of the oral cavity and respiratory tract. Importantly, all of the strains are more susceptible to the tested AgNPs than to the control solution of $\mathrm{AgNO}_{3}$ as observed within the same concentration range (MIC $5.0-100.0 \mu \mathrm{g} / \mathrm{mL}$ ). Moreover, AgNPs-LA were effective against Staphylococcus epidermidis and Streptococcus mutans 1-day biofilm at concentration nontoxic to gingival fibroblast cells. Our study suggests potential usefulness of AgNPs in dental practice provided that pharmacological activity and risk assessment are carefully evaluated.

\section{Acknowledgment}

This research was supported by the Founds from The Medical University of Gdansk nr: MN-01-0197/08/259 and St-46.

\section{Competing Interests}

The authors declare no competing interest.

\section{References}

1. Alexander JW. History of the medical use of silver. Surg Infect. 2009; 10: 289-292.

2. Ip M, Lui SL, Poon VK, et al. Antimicrobial activities of silver dressings: an in vitro comparison. J Med Microbiol, 2006; 55: 59-63.

3. Lu Z, Rong K, Li J, et al. Size-dependent antibacterial activities of silver nanoparticles against oral anaerobic pathogenic bacteria. J Mater Sci Mater Med. 2013; 24: 1465-1471.

4. Russell AD, Hugo WB. Antimicrobial activity and action of silver. Prog Med Chem. 1994; 31: 351-370.

5. García-Contreras R, Argueta-Figueroa L, Mejía-Rubalcava C, et al. Perspectives for the use of silver nanoparticles in dental practice. Int Dent J. 2011; 61: 297-301.

6. Service RF. Nanotoxicology. Nanotechnology grows up. Science. 2004; 304: $1732-1734$

7. Saion E, Gharibshaki E, Naghavi K. Size-Controlled and Optical Properties of Monodispersed Silver Nanoparticles Synthesized by the Radiolytic Reduction Method. Int J Mol Sci. 2013; 14: 7880-7896.

8. Brandt $\mathrm{O}$, Mildner $\mathrm{M}$, Egger AE, et al. Nanoscalic silver possesses broad-spectrum antimicrobial activities and exhibits fewer toxicological side effects than silver sulfadiazine. Nanomedicine. 2012; 8: 478-488.

9. Marambio-Jones C, Hoek EMV. A review of the antibacterial effects of silver nanomaterials and potential implications for human health and the environment. J Nanopart Res. 2010; 12: 1531-1551.

10. Mohanty S, Mishra S, Jena P, et al. An investigation on the antibacterial, cytotoxic, and antibiofilm efficacy of starch-stabilized silver nanoparticles. Nanomedicine. 2012; 8: 916-924.

11. Gajbhiye M, Kesharwani JA, Ingle A, et al. Fungus-mediated synthesis of silver nanoparticles and their activity against pathogenic fungi in combination with fluconazole. Nanomedicine. 2009; 5: 382-386.

12. Fayaz AM, Balaji K, Girilal M, et al. Biogenic synthesis of silver nanoparticles and their synergistic effect with antibiotics: a study against gram-positive and gram-negative bacteria. Nanomedicine. 2010; 6: 103-109.

13. Nanda A, Saravanan M. Biosynthesis of silver nanoparticles from Staphylococcus aureus and its antimicrobial activity against MRSA and MRSE. Nanomedicine. 2009; 5: 452-456.

14. Strydom SJ, Rose WE, Otto DP, et al. Poly(amidoamine) dendrimer-mediated synthesis and stabilization of silver sulfonamide nanoparticles with increased antibacterial activity. Nanomedicine. 2013; 9: 85-93.

15. Slane J, Vivanco J, Rose W, et al. Mechanical, material, and antimicrobial properties of acrylic bone cement impregnated with silver nanoparticles. Mater Sci Eng C Mater Biol Appl. 2015; 48: 188-196.

16. Shawky HA, Soha MB, Gihan AELB, et al. Evaluation of Clinical and Antimicrobial Efficacy of Silver Nanoparticles and Tetracycline Films in the Treatment of Periodontal Pockets. IOSR J Dental Med Sci. 2015; 14: 113-123.

17. Saga T, Yamaguchi K. History of Antimicrobial Agents and Resistant Bacteria. Japan Med Assoc J. 2009; 52: 103-108.

18. Rautema $\mathrm{R}$, Lauhio A, Cullinan MP, et al. Oral infections and systemic disease-an emerging problem in medicine. Clin Microbiol Infect. 2007; 13: 1041-1047.

19. Eaton KA. Global oral public health-the current situation and recent developments. J Public Health Policy. 2012; 33: 382-386.

20. Nikolaev YuA, Plakunov VK. Biofilm - "City of Microbes" or an Analogue of Multicellular Organisms? Microbiology. 2007; 76: 125-138

21. Potera C. Antibiotic resistance: Biofilm dispersing agent rejuvenates older antibiotics. Environ Health Perspect. 2010; 118: A288-A291.

22. Li X, Kolltveit KM, Tronstad L, et al. Systemic diseases caused by oral infection. Clin Microbiol Rev. 2000; 13: 547-558.

23. Corrêa JM, Mori M, Sanches HL, et al. Silver nanoparticles in dental biomaterials. Int J Biomater. 2015; 2015: 1-9.

24. Singh S, Nalwa HS. Nanotechnology and health safety-toxicity and risk assessments of nanostructured materials on human health. J Nanosci Nanotechnol. 2007; 7: 3048-3070. 
25. Inkielewicz-Stepniak I, Santos-Martinez MJ, Medina C, et al. Pharmacological and toxicological effects of co-exposure of human gingival fibroblasts to silver nanoparticles and sodium fluoride. Int J Nanomedicine, 2014; 9: 1677-1687.

26. Zhang $\mathrm{T}$, Wang $\mathrm{L}$, Chen $\mathrm{Q}$, Chen $\mathrm{Ch}$. Cytotoxic potential of silver nanoparticles. Yonsei Med J. 2014; 55: 283-291.

27. Taleghani F, Yaraii R, Sadeghi R, et al. Cytotoxicity of silver nanoparticles on human gingival epithelial cells: An in vitro study. J Dent Sci. 2014; 32: 30-36.

28. Grade S, Eberhard J, Jakobi J, et al. Alloying colloidal silver nanoparticles with gold disproportionally controls antibacterial and toxic effects. Goll Bull. 2014; 47: 83-93.

29. Jiang J, Oberdörster G, Biswas P. Characterization of size, surface charge, and agglomeration state of nanoparticle dispersions for toxicological studies. J Nanopart Res. 2009; 11: 77-89.

30. [Internet] Nanocomposix http://nanocomposix.eu/collections/silverspheres/products/10-nm-silver-nanospheres\#example-specification-sheet.

31. Holdeman LV, Moore WEC. Anaerobe laboratory manual. Blacksburg, Virginia: VPI. Anaerobe Laboratory; 1977.

32. Holt JG. Bergey's manual of determinative bacteriology. Baltimore: Williams and Wilkins; 1994

33. Forbes BA, Sahn DF, Weissfeld AS. Bailey and Scott's diagnostic microbiology, 12th ed. St. Louis, MO: Mosby Elsevier; 2007: 778-781.

34. Hecht DW, Citron DM, Cox M, et al. Methods for antimicrobial susceptibility testing of anaerobic bacteria: approved standards, 8rd ed. USA: Clinical and Laboratory Standards Institute: Wayne PA 19087; 2012.

35. Murdock RC, Braydich-Stolle L, Schrand AM, et al. Characterization of nanomaterial dispersion in solution prior to in vitro exposure using dynamic light scattering technique. Toxicol Sci. 2007; 101: 239-253.

36. Ates M, Daniels J, Arslan Z, et al. Comparative evaluation of impact of $\mathrm{Zn}$ and $\mathrm{ZnO}$ nanoparticles on brine shrimp (Artemia salina)larvae: effects of particle size and solubility on toxicity. Environ Sci Process Impacts. 2013; 15: 225-233.

37. Jiang J, Oberdörster G, Biswas P. Characterization of size, surface charge, and agglomeration state of nanoparticle dispersions for toxicological studies. J Nanopart Res. 2009; 11: 77-89.

38. Chiang SL, Jiang SS, Wang YJ, et al. Characterization of arecoline-induced effects on cytotoxicity in normal human gingival fibroblasts by global gene expression profiling. Toxicol Sci. 2007; 100: 66-74.

39. Urcan E, Haertel U, Styllou M, et al. Real-time xCELLigence impedance analysis of the cytotoxicity of dental composite components on human gingival fibroblasts. Dent Mater. 2010; 26: 51-58.

40. Jaiswal S, Duffy B, Jaiswal AK, et al. Enhancement of the antibacterial properties of silver nanoparticles using beta-cyclodextrin as a capping agent. Int J Antimic Agents. 2010; 36: 280-283.

41. Khlebtsov N, Dykman L. Biodistribution and toxicity of engineered gold nanoparticles: a review of in vitro and in vivo studies. Chem Soc Rev. 2011; 40: $1647-1671$

42. Langer R, Tirrell DA. Designing materials for biology and medicine. Nature. 2004; 428: 487-492.

43. Liu $X$, Huang $H$, Liu $G$, et al. Multidentate zwitterionic chitosan oligosaccharide modified gold nanoparticles: stability, biocompatibility and cell interactions. Nanoscale. 2013; 5: 3982-3991.

44. Spacciapoli P, Buxton D, Rothstein D, Friden P. Antimicrobial activity of silver nitrate against periodontal pathogens. J Periodontal Res. 2001; 36: 108-113.

45. Duffin S. Back to the future: the medical management of caries introduction. J Calif Dent Assoc. 2012; 40: 852-858.

46. Chu CH, Gao SS, Li SK, Wong MC, Lo EC. The effectiveness of the biannual application of silver nitrate solution followed by sodium fluoride varnish in arresting early childhood caries in preschool children: study protocol for a randomised controlled trial. Trials. 2015; 16: 426.

47. De Jong $\mathrm{WH}$, Borm PJ. Drug delivery and nanoparticles: applications and hazards. Int J Nanomedicine. 2008; 3: 133-149.

48. Ahmad T. Reviewing the tannic acid mediated synthesis of metal nanoparticles. J Nanotechnol. 2014; 2014:1-11.

49. Anand N, Ramudu P, Reddy KHP, et al. Gold nanoparticles immobilized on lipoic acid functionalized SBA-15: Synthesis, characterization and catalytic applications. Appl Catal A. 2013; 454: 119-126.

50. Abiodun-Solanke IMF, Ajayi DM, Arigbede AQ. Nanotechnology and its application in dentistry. Ann Med Health Sci Res. 2014; 4: S171-S177.

51. Besinis A, De Peralta T, Tredwin CJ, et al. Review of nanomaterials in dentistry: Interactions with the oral microenvironment, clinical applications, hazards and benefits. ACS Nano. 2015; 9: 2255-2289.

52. Gliga AR, Skoglund S, Wallinder IO, et al. Size-dependent cytotoxicity of silver nanoparticles in human lung cells: the role of cellular uptake, agglomeration and Ag release. Part Fibre Toxicol 2014; 11: 11

53. Yu M, Huang S, Yu KJ, et al. Dextran and Polymer Polyethylene Glycol (PEG) Coating Reduce Both 5 and $30 \mathrm{~nm}$ Iron Oxide Nanoparticle Cytotoxicity in 2D and 3D Cell Culture. Int J Mol Sci. 2012; 13: 5554-5570.

54. DeBrosse MC, Comfort KK, Untener EA, et al. High aspect ratio gold nanorods displayed augmented cellular internalization and surface chemistry mediated cytotoxicity. Mater Sci Eng C Mater Biol Appl. 2013; 33: 4094-4100.

55. Lee K, Browning LM, Nallathamby PD, et al. Study of charge-dependent transport and toxicity of peptide-functionalized silver nanoparticles using zebrafish embryos and single nanoparticle plasmonic spectroscopy. Chem Res Toxicol. 2013; 26: 904-917.
56. Pettegrew C, Dong Z, Muhi MZ, et al. Silver Nanoparticle Synthesis Using Monosaccharides and Their Growth Inhibitory Activity against Gram-Negative and Positive Bacteria. ISRN Nanotechnology. 2014; 1-8.

57. El Badawy AM, Silva RG, Morris B, et al. Surface charge-dependent toxicity of silver nanoparticles. Environ Sci Technol. 2011; 45: 283-287.

58. Abdel-Mohsen AM, Hrdina R, Burgert L, et al. Antibacterial activity and cell viability of hyaluronan fiber with silver nanoparticles. Carbohydr Polym. 2013; 92: 1177-1187.

59. Amato E, Diaz-Fernandez YA, Taglietti A, et al. Synthesis, characterization and antibacterial activity against Gram-positive and Gram-negative bacteria of biomimetically coated silver nanoparticles. Langmuir. 2011; 27: 9165-9173.

60. Goswami SR, Sahareen T, Singh M, et al. Role of biogenic silver nanoparticles in disruption of cell-cell adhesion in Staphylococcus aureus and Escherichia coli biofilm. J Ind Eng Chem. 2015; 26: 73-80.

61. Pérez-Díaz MA, Boegli L, James G, et al. Silver nanoparticles with antimicrobial activities against Streptococcus mutans and their cytotoxic effect. Mater Sci Eng C Mater Biol Appl. 2015; 55: 360-366.

62. Franci G, Falanga A, Galdiero S, et al. Silver nanoparticles as potential antibacterial agents. Molecules. 2015; 20: 8856-8874

63. Ogawa A, Furukawa S, Fujita S, et al. Inhibition of Streptococcus mutans biofilm formation by Streptococcus salivarius FruA. Appl Environ Microbiol. 2011; 77: 1572-1580.

64. McCormack MG, Smith AJ, Akram AN, et al. Staphylococcus aureus and the oral cavity: an overlooked source of carriage and infection? Am J Infect Control. 2015; 43: 35-37.

65. Archer NK, Mazaitis MJ, Costerton JW, et al. Staphylococcus aureus biofilms: properties, regulation, and roles in human disease. Virulence. 2011; 2: 445-459.

66. Loberto JCS, Martins CAP, Santos SSF, et al. Staphylococcus spp. in the oral cavity and periodontal pockets of chronic periodontitis patients. Braz J Microbiol. 2004; 35: 64-68.

67. Cuesta AI, Jewtuchowicz V, Brusca MI, et al. Prevalence of Staphylococcus spp and Candida spp in the oral cavity and periodontal pockets of periodontal disease patients. Acta Odontol Latinoam. 2010; 23:20-26.

68. Padovani GC, Feitosa VP, Sauro S, et al. Advances in Dental Materials through Nanotechnology: Facts, Perspectives and Toxicological Aspects. Trends Biotechnol. 2015; 33: 621-636.

69. Hernández-Sierra JF, Ruiz F, Pena DC, et al. The antimicrobial sensitivity of Streptococcus mutans to nanoparticles of silver, zinc oxide, and gold. Nanomedicine. 2008; 4: 237-240.

70. Espinosa-Cristóbal LF, Martínez-Castañón GA, Téllez-Déctor EJ, et al. Adherence inhibition of Streptococcus mutans on dental enamel surface using silver nanoparticles. Mater Sci Eng C Mater Biol Appl. 2013; 33: 2197-2202.

71. Kalishwaralal K, BarathManiKanth S, Pandian SR, et al. Silver nanoparticles impede the biofilm formation by Pseudomonas aeruginosa and Staphylococcus epidermidis. Colloids Surf B Biointerfaces. 2010; 79: 340-344.

72. Gurunathan S, Han JW, Kwon DN, et al. Enhanced antibacterial and anti-biofilm activities of silver nanoparticles against Gram-negative and Gram-positive bacteria. Nanoscale Res Lett. 2014; 9: 373. 